\title{
Identities among actin-encoding cDNAs of the Nile tilapia (Oreochromis niloticus) and other eukaryote species revealed by nucleotide and amino acid sequence analyses
}

\author{
Andréia B. Poletto ${ }^{1}$, Adriane P. Wasko ${ }^{2}$, Claudio Oliveira ${ }^{1}$, Alexandre Azevedo ${ }^{1}$, Robson F. Carvalho ${ }^{1}$, \\ Maeli Dal Pai Silva ${ }^{1}$, Fausto Foresti ${ }^{1}$ and Cesar Martins ${ }^{1}$ \\ ${ }^{1}$ Departamento de Morfologia, Instituto de Biociências, Universidade Estadual Paulista, Campus de \\ Botucatu, Botucatu, SP, Brazil. \\ ${ }^{2}$ Departamento de Genética, Instituto de Biociências, Universidade Estadual Paulista, Campus de Botucatu, \\ Botucatu, SP, Brazil.
}

\begin{abstract}
Actin-encoding cDNAs of Nile tilapia (Oreochromis niloticus) were isolated by RT-PCR using total RNA samples of different tissues and further characterized by nucleotide sequencing and in silico amino acid (aa) sequence analysis. Comparisons among the actin gene sequences of $O$. niloticus and those of other species evidenced that the isolated genes present a high similarity to other fish and other vertebrate actin genes. The highest nucleotide resemblance was observed between $O$. niloticus and $O$. mossambicus $\alpha$-actin and $\beta$-actin genes. Analysis of the predicted aa sequences revealed two distinct types of cytoplasmic actins, one cardiac muscle actin type and one skeletal muscle actin type that were expressed in different tissues of Nile tilapia. The evolutionary relationships between the Nile tilapia actin genes and diverse other organisms is discussed.
\end{abstract}

Key words: actin, expression pattern, Nile tilapia, Oreochromis niloticus.

Received: August 22, 2006; Accepted: April 18, 2007.

Actin is a ubiquitous protein of eukaryotic cells that has a crucial role in muscle contraction, cell motility, cytoskeletal structure, cell division, intracellular transport, and cell differentiation (Herman, 1993). In yeast and some protozoans, actin is encoded by a single gene only (Hightower and Meagher, 1986; Reece et al., 1997). However, in the nuclei of all animals, plants and in many protozoans examined to date, actin proteins are encoded by a multigene family. In these organisms it seems that actin isoforms are encoded by a set of structurally related genes that resulted from gene duplications followed by functional divergence (Hightower and Meagher, 1986). The number of actin isoforms varies greatly in different lineages. While mammals posses at least six different isoforms (Vandekerckhove and Weber, 1978), teleost fishes contain at least nine (Venkatesh et al., 1996) and echinoderm genomes at least eight (Fang and Brandhorst, 1994) distinct actin isoforms. Similarly, insects have at least six actin genes (Fyrberg et al., 1980). The actin gene family of plants is much larger, com-

Send correspondence to Cesar Martins. Departamento de Morfologia, Instituto de Biociências, Universidade Estadual Paulista, Campus de Botucatu, 18618-000 Botucatu, SP, Brazil. E-mail: cmartins@ibb.unesp.br. prising 8-44 genes, depending on the taxon (Reece et al., 1992; Drouin and de Sá, 1996).

The actin gene family can be divided into two broad categories: cytoplasmic $(\beta$ and $\gamma$ ) and muscle $(\alpha)$ type actins. Invertebrate muscle and cytoplasmic actins seem to be more similar to chordate cytoplasmic actins than to chordate muscle actins (Vandekerckhove and Weber, 1984). It has been suggested that the muscle actins of arthropods differ from the muscle actins of deuterostomes to such an extent that two independent divergence events of muscle actin genes probably occurred, one within the protostome lineage and one within the deuterostome lineage (Mounier et al., 1992).

Although there are data on the evolution of mammalian actin genes, the evolutionary origin, pattern of organization, and the diversity of these genes in other vertebrates, especially fishes, remain to be investigated. To date, an in-depth research on the diversity of actin gene types and tissue expression profiles in a fish species was only performed on Takifugu rubripes, revealing nine different actin genes: six muscle-type actin genes that include two $\alpha$-skeletal actins, three $\alpha$-cardiac actins, an $\alpha$-anomalous testis-type actin, and three cytoplasmic actins that include two 
$\beta$-cytoplasmic actins and one $\beta$-cytoplasmic vascular-type actin (Venkatesh et al., 1996). The purpose of the present study was the isolation and characterization of distinct actin cDNAs from different tissues of the Nile tilapia (Oreochromis niloticus) - one of the most important food fish species intensively exploited in tropical and subtropical aquaculture (Pullin, 1991) - not only to enhance our knowledge of the species, but also to provide a better understanding of the organization of the actin multigene family in fish genomes.

Total RNA samples were obtained from different tissues (gills, heart, ovaries, skeletal muscle, liver, and brain) of two adult individuals of Oreochromis niloticus using TRIzol reagent (Gibco-Brl Life Technologies), following the manufacturer's instructions. First-strand cDNA synthesis reactions were performed with the SuperScript FirstStrand Synthesis System for RT-PCR (Invitrogen Life Technologies) using random hexamer primers. cDNA amplification was performed using the primer sets $\alpha \mathrm{ActF}$ ( $5^{\prime}$ ATGAGACTACCGCCCTTGTG-3') and $\alpha$ ActR (5' -AAT CCACATCTGCTGGAAGG-3') for $\alpha$-actin gene amplification, and $\beta A c t F$ (5'-TGTTGACAATGGATCCGGTA3') and $\beta A c t R$ (5'-CTGCTGGAAGGTGGAGAGAG-3') for $\beta$-actin gene amplification. Both primer sets were designed using the software Primer3 (Rozen and Skaletsky, 2000) based on $\alpha$-actin and $\beta$-actin gene sequences described previously for T. rubripes (Venkatesh et al., 1996). RT-PCR products were electrophoresed and visualized on a $1 \%$ agarose gel, purified and ligated into pCR2.1 plasmid (TA Cloning Kit, Invitrogen) used to transform DH5 $\alpha E$. coli competent cells. Plasmid DNA was purified with the Wizard Plus SV Minipreps DNA Purification System Kit (Promega) and submitted to nucleotide sequencing on an ABI 377 Automated DNA Sequencer (Applied Biosystems).

Nucleic acid and amino acid sequences of $O$. niloticus were analyzed using BLASTn and BLASTx (Altschul et al., 1990). Additionally, sequences from different organisms obtained from GenBank, were aligned with $O$. niloticus sequence data using the software ClustalW (Thompson et al., 1994); alignment was checked by eye and adjusted as necessary. Phylogenetic analyses using the putative aa sequences derived from $O$. niloticus clones and other aa sequences from previously published actin genes in GenBank were performed using MEGA version 3.1 (Kumar et al., 2004). Phylogenetic trees were constructed using the neighbor-joining method (Saitou and Nei, 1987).

RT-PCR of Oreochromis niloticus cDNA samples, obtained from total RNA extracted from gills, liver, heart, ovary, skeletal muscle and brain, was performed using the two sets of primers $\alpha A c t F / \alpha A c t R$ and $\beta A c t F / \beta A c t R$ in order to amplify $\alpha$-actin and $\beta$-actin gene sequences, respectively. Irrespective of the tissue or the primer set used, all PCR amplifications resulted in one fragment of approxi- mately 1,100 base pairs (bp) that was cloned and sequenced.

A total of 11 clones were isolated and sequenced in both directions from two individuals of $O$. niloticus. These represented three skeletal muscle type $\alpha$-actins from gills (On1a7, On1a8, and On1a9); one skeletal muscle type $\alpha$-actin from heart $(O n 3 \mathrm{a} 8)$; one cardiac muscle type $\alpha$ actin from heart $(\mathrm{On} 3 \mathrm{a} 10 \mathrm{c})$; one $\beta$-actin from ovary (On4b1); four skeletal muscle type $\alpha$-actins (On5a18, On5a10, On5a3 and On5a5) and one $\beta$-actin (On5b2) from skeletal muscle tissue (Figure 1). The nucleotide sequences were deposited in the GenBank database under the accession numbers EF206791-EF206801. The obtained sequences of the amplified cDNAs of $O$. niloticus revealed segments ranging in size from 884 to $1,063 \mathrm{bp}$. The differences in the sequence sizes were due to failures in the sequencing procedure.

Searches in the NCBI database by means of BLASTn indicated that the isolated cDNA nucleotide sequences from $O$. niloticus were very similar to several fish actin gene sequences, especially to $\alpha$-actins and $\beta$-actins of $O$. mossambicus (99\% mean nucleotide identity between the two species). The putative amino acid sequences of the isolated cDNAs from $O$. niloticus were also compared to skeletal actin1, skeletal actin2, cardiac1 alpha actin, cytoplasmic actin1 and cytoplasmic actin2 genes of $T$. rubripes (Venkatesh et al., 1996), which resulted in a $98,4 \%$ mean identity (Figure 1).

Although the nucleotide sequences of the isolated cDNAs of $O$. niloticus and the actin genes of $T$. rubripes differ by several nucleotides, their inferred aa sequences present a high degree of similarity, approximately $98 \%$, since most nucleotide variation corresponds to synonymous substitutions and, thus, their aa residues are mostly identical (Figure 1). Diagnostic aa positions that distinguish $\alpha$-muscle actin from $\beta$-cytoplasmic actin of Nile tilapia could be observed (Figure 1). These aa positions were also identified in the isolated cDNAs of $T$. rubripes (Venkatesh et al., 1996). Most amino acids that distinguish fish $\alpha$-striated muscle actins from $\beta$-cytoplasmic actins correspond to those that also distinguish mammalian $\alpha$ - and $\beta$-actins (Mounier and Sparrow, 1997). Diagnostic amino acids 281,321 and 325 that distinguish $T$. rubripes $\beta$-cytoplasmic actin2 from $\beta$-cytoplasmic actin1 were identified in the isolated cDNA sequence On $4 \mathrm{~b} 1$ of $O$. niloticus, which validates the occurrence of a second type of cytoplasmic actin gene expressed in fish species. This is a novel finding, since the expression of $\beta$-cytoplasmic actin 2 has not yet been reported, only its genomic sequence (Venkatesh et al., 1996).

A molecular phylogenetic analysis of some actin aa sequences was performed to examine the evolutionary relationship of the actin isoforms isolated from Nile tilapia and several other eukaryote species (Table 1, Figure 2). The 


\begin{tabular}{|c|c|c|c|c|c|c|c|c|c|}
\hline 25 a 3 & --- E TTAL & VCDNGSGLVK & AGFAGDDAPR & AVF PS IVGRP & RHQGVMV GMG & QKDSYVGDEA & QS KRGIL TLK & YPIEHG I I TN & WD DME KIV \\
\hline & $---\ldots \ldots$ & $\ldots \ldots \ldots$ & ......... & $\ldots \ldots \ldots$ & $\ldots \ldots \ldots$ & $\ldots \ldots \ldots$ & ........ & & \\
\hline & $--\ldots \ldots$ & $\cdots \cdots \cdots$ & n....... & $\cdots \cdots$ & $\cdots \cdots$ & $\cdots$ & $\ldots \ldots \ldots$ & $\cdots \cdots$ & \\
\hline &....-- & $\cdots \cdots \cdots \cdots$ & …… & $\cdots \cdots \cdots \cdots$ & $\ldots \ldots \ldots \ldots$ & & $\cdots \cdots \cdots$ & $\cdots$ & \\
\hline & $--\ldots$ & $\cdots \cdots \cdots \cdots$ & $\ldots \ldots \in \ldots$ & $\cdots \cdots \cdots$ & $\cdots \cdots \cdots$ & $\cdots A \ldots$ & $\cdots \cdots \cdots$ & $\cdots \cdots \cdots$ & $\cdots \cdot$ \\
\hline & $-\ldots \ldots$ & a.m. & ……m. & ${ }^{\prime} \ldots \ldots m m$ & ……m. & ${ }^{\prime} \ldots \ldots m m$ & $\ldots \ldots \ldots$ & & \\
\hline $25 a 18$ & $-----\ldots$ & $\ldots \ldots \ldots$ & $\ldots \ldots \ldots \ldots$ & $\ldots \ldots \ldots$ & $\ldots \ldots \ldots$ & anman & $\cdots \cdots \cdots$ & $\cdots$ & \\
\hline$x \quad \alpha-a c 1$ & MCDDD $\ldots \ldots$ & $\cdots \ldots \ldots$ & $\ldots \ldots \ldots \ldots$ & ....... & $\ldots \ldots \ldots$ & $\cdots \cdots \cdots$ & & & \\
\hline & DDD ..... & & & $\cdots \cdots$ & $\cdots$ & $\ldots \ldots \cdots$ & $\ldots$ & $\cdots$ & .. \\
\hline & & & $\cdots$ & $\cdots \cdots$ & $\cdots$ & $\cdots$ & $\cdots$ & $\cdots$ & \\
\hline & MCDDD... & -v....MMCE & ${ }_{\mathrm{g}} \ldots \mathrm{p}_{\ldots} \ldots \ldots$ & …m. & $\begin{array}{l}\ldots \ldots m \\
\ldots \ldots m\end{array}$ & $\begin{array}{l}\ldots \ldots m \\
\ldots \ldots m\end{array}$ & $\begin{array}{l}\cdots \cdots \\
\cdots \cdots\end{array}$ & $\begin{array}{l}\cdots \cdots \\
\cdots\end{array}$ & $\begin{array}{l}\cdots \ldots \ldots \\
\ldots \ldots \ldots\end{array}$ \\
\hline & --MDD.IA. . & . v.....MC. & & & & & & & \\
\hline 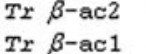 & --MED. IA. . & v. . . mc. & & & & & & v. & \\
\hline $\begin{array}{l}=\beta-8 \\
25 \mathrm{~b} 2\end{array}$ & & $-v \ldots$. & ......... & . צ...... & $\ldots \ldots \ldots$ & $\ldots \ldots \ldots$ & 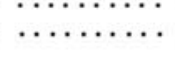 & ……v. & $\cdots \cdots$ \\
\hline & & & & & & & & & \\
\hline & $\ldots \ldots \ldots$ & ....F.A & $\ldots \ldots \ldots$ & & & & & & \\
\hline & $\cdots$ & $\ldots \ldots \ldots$ & $\ldots \ldots \ldots$ & $\ldots \ldots \ldots$ & $\ldots \ldots \ldots$ & $\ldots \ldots \ldots N$ & $\ldots \ldots \ldots$ & $\cdots \cdots$ & \\
\hline & $\cdots$ & …... & $\ldots \ldots \ldots$ & $\cdots \cdots$ & .......... & ......... & $\ldots \ldots \ldots$ & $\cdots \cdots$ & $-x_{0}$ \\
\hline & $\cdots$ & $\cdots \cdots \cdots A$ & $\cdots \cdots \cdots$ & $\cdots \cdots \mathrm{T}$ & $\cdots \cdots \cdots$ & $\cdots \cdots \cdots$ & 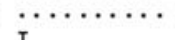 & ......... & . v. \\
\hline & $\cdots$ & $\cdots \cdots$ & $\cdots$ & & & $\begin{array}{l}\cdots \\
\cdots\end{array}$ & $\cdots$ & $\cdots$ & 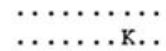 \\
\hline & $\cdots$ & $\cdots$ & . $\ldots$ & ... & & $\cdots$ & $\cdots$ & $\cdots \cdots$ & $\cdots \cdots$ \\
\hline & $\cdots$ & A A & $\ldots \ldots$ & ... & & & 皮 & & $\cdots \cdots$ \\
\hline 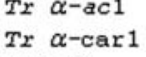 & $\ldots$ & $\mathrm{A}$ & 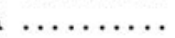 & . T.. & & & 5... & & \\
\hline $25 \mathrm{a}$ & $\cdots$ & $\ldots \ldots \ldots$ & ........... & …… & ........ & $\ldots \ldots \ldots$ & ........ & $\ldots \ldots$ I. & $\cdots$ \\
\hline & s......... & $\ldots \ldots \ldots \mathrm{A}$ & $\cdots$ & & & & $\cdots$ & & $\cdots$ \\
\hline & . & & & & & & & & \\
\hline 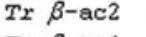 & $\cdots$ & ...v.... & $\ldots \ldots \ldots$ & …… & $\mathbf{T} \ldots \ldots \ldots$ & $\ldots \ldots \ldots \ldots$ & $\ldots \ldots r$ & .I. . & $\ldots \ldots \ldots$ L. \\
\hline & $\cdots$ & …v.... & & …… & T.. & $\cdots$ & ...M.s... & I. . . & $\ldots \ldots \mathrm{L}$ \\
\hline $25 \mathrm{~b} 2$ & & $\cdots \mathrm{A}$ & & & & & & & \\
\hline & INY & RGY & SFVTTAERE I & VRD & & L EK & & TIGN & \\
\hline & $\cdots$ & & & $\cdots$ & $\cdots$ & $\ldots$ & . & & \\
\hline & $\cdots$ & $\cdots$ & $\cdots \cdots$ & $\cdots$ & & $\cdots$ & $\cdots$ & & $\cdots$ \\
\hline & D. & - & $\cdots$ & $\cdots$ & & $\cdots$ & $\cdots$ & $\ldots \ldots \ldots$ & $\cdots$ \\
\hline & . V . . . D. & $\cdots 1$ & …… & $\ldots$. . . & & A. & ....G. & . & \\
\hline & $\cdots \cdots$ & ........ & $\cdots \cdots \cdots \cdots$ & $\cdots$ & & A.. & $\cdots$ & $\cdots \cdots \cdots$ & $\cdots$ \\
\hline & ….... & $\cdots$ & $\cdots$ & & & & & $\cdots$ & $\cdots$ \\
\hline : & $\ldots \ldots \ldots$ D. & & & & & & & & \\
\hline & ....... & $\cdots$ & $\ldots \ldots$ & K... & & $\cdots$ & $\cdots$ & & \\
\hline & . & $\cdots$ s & & & & & & & \\
\hline & $\cdots$ & & & & & & $\cdots$ & & \\
\hline & .D. & & .т. т.... & . к... & & & G... & & \\
\hline : & …... & $\cdots$ & $\ldots \mathbf{T} \ldots \ldots$ & $\ldots \ldots$ к... & A. WOQ G & . A $\ldots \ldots$ & ....G. G. & $\ldots \ldots \ldots$ &. $\mathbf{A} \ldots \ldots \mathbf{L}$ \\
\hline $\begin{array}{l}\beta-\mathrm{ac} 1 \\
25 \mathrm{~b} 2\end{array}$ & $\begin{array}{l}\text { …… } \\
\text { …… }\end{array}$ & …m. & $\begin{array}{l}\ldots \mathbf{T} \ldots \ldots \\
\ldots \mathbf{T} \ldots \ldots \\
\end{array}$ & $\begin{array}{l}\ldots \ldots \text { к... } \\
\ldots \ldots \text { к. }\end{array}$ & $\begin{array}{l}A \ldots Q \ldots G \\
. A \ldots Q \cdots G\end{array}$ & $\begin{array}{l}. A \ldots \ldots \ldots \\
. A \\
.\end{array}$ & $\begin{array}{l}\ldots \ldots \text { G... } \\
\ldots \ldots \text { G. }\end{array}$ & & $\begin{array}{l}\text {.A. } \ldots \text { I } \\
. \mathrm{A} \ldots \ldots \text { I }\end{array}$ \\
\hline & & & & & & & & & \\
\hline & TA & & $\mathrm{INV}$ & & EIT & KIK & KYS & & LST \\
\hline & $\begin{array}{l}\cdots \\
\cdots\end{array}$ & $\cdots$ & $\cdots$ & $\cdots$ & & $\cdots$ & $\cdots \cdots$ & & $\cdots \cdots$ \\
\hline & & & & & & & & & \\
\hline & & & & & & & & & \\
\hline & & & $\cdots$ & & & $\cdots$ & $\cdots \cdots$ & & \\
\hline & & & & & & & & & \\
\hline & & & & & & & & & \\
\hline c $c$ & & & $\cdots$ & $\cdots$ & & $\cdots$ & ........... & . . A. & 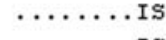 \\
\hline & & & & & & & & & \\
\hline & & & & & & & & & \\
\hline & & & & & & s... & $\cdots \cdots$ & - & \\
\hline & $\ldots \mathrm{c} \ldots \mathrm{T}$ & F....... & $\ldots \ldots \ldots \mathbf{T}$ & & & s... & $\ldots \ldots \ldots$ & ....... & $\cdots \cdots \cdots$ \\
\hline $25 \mathrm{~b} 2$ & & & & & & & & & \\
\hline
\end{tabular}

Figure 1 - Alignment of putative amino acid sequences of actin cDNAs isolated from Oreochromis niloticus (On) and cDNAs of Takifugu rubripes (Tr) obtained from NCBI database. Dashes indicate gaps introduced in the sequences to optimize the alignment. Diagnostic aa positions that distinguish $\alpha$-muscle actin from $\beta$-cytoplasmic actins are in bold face type. Sources and accession numbers for the actin sequences are described in Materials and Methods. 
Table 1 - Species and accession numbers of actin cDNA sequences obtained from GenBank.

\begin{tabular}{|c|c|}
\hline Species & $\begin{array}{l}\text { Actin type and GenBank } \\
\text { entries }\end{array}$ \\
\hline Ambystoma mexicanum (salamander) & $\alpha$-actin: AF276076 \\
\hline Arabidopsis thaliana (arabidopsis) & $\beta$-actin: NM179953 \\
\hline Bos taurus (cattle) & $\begin{array}{l}\alpha \text {-actin: NM174225; } \\
\beta \text {-actin: AY141970 }\end{array}$ \\
\hline Ciona intestinalis (ascidian) & $\alpha$-actin: AK115759 \\
\hline Danio rerio (zebrafish) & $\begin{array}{l}\alpha \text {-actin: BC065435; } \\
\beta \text {-actin: NM131031 }\end{array}$ \\
\hline Dictyostelium discoideum (myxamoeba) & $\beta$-actin: XM632417 \\
\hline Dipsosaurus dorsalis (iguana) & $\alpha$-actin: AF503591 \\
\hline Drosophila melanogaster (fruit fly) & $\begin{array}{l}\alpha \text {-actin: NM079643; } \\
\beta \text {-actin: NM079076 }\end{array}$ \\
\hline Gallus gallus (chicken) & $\begin{array}{l}\alpha \text {-actin: X02212; } \\
\beta \text {-actin: NM205518 }\end{array}$ \\
\hline Homo sapiens (human) & $\begin{array}{l}\alpha \text {-actin: BC012597; } \\
\beta \text {-actin: NM001101 }\end{array}$ \\
\hline Mus musculus (mouse) & $\begin{array}{l}\alpha \text {-actin: M12866; } \\
\beta \text {-actin: NM007393 }\end{array}$ \\
\hline Oryza sativa (rice) & $\beta$-actin: AB047313 \\
\hline Rattus norvegicus (rat) & $\begin{array}{l}\alpha \text {-actin: NM019212; } \\
\beta \text {-actin: NM031144 }\end{array}$ \\
\hline Spodoptera exigua (moth) & $\alpha$-actin: AY507963 \\
\hline $\begin{array}{l}\text { Strongylocentrotus purpuratus } \\
\text { (sea urchin) }\end{array}$ & $\begin{array}{l}\alpha \text {-actin: J01202; } \\
\beta \text {-actin: NM214529 }\end{array}$ \\
\hline Sus scrofa (pig) & $\beta$-actin: AY550069 \\
\hline Takifugu rubripes (fugu) & $\begin{array}{l}\alpha \text {-actins: U38850, U38958, } \\
\text { U38959, U38960, U38961; } \\
\beta \text {-actins: U37499, U38848, } \\
\text { U38849 }\end{array}$ \\
\hline Xenopus laevis (African clawed frog) & $\alpha$-actin: BC041197 \\
\hline Xenopus tropicalis (pipid frog) & $\beta$-actin: $\mathrm{BC} 064155$ \\
\hline
\end{tabular}

myxamoeba species Dictyostelium discoideum was used as an outgroup. The animal actins were clearly discriminated from plant actins in $95 \%$ of the recovered trees. Not surprisingly, a close relationship was observed between Nile tilapia and other vertebrate $\alpha$-actins. The clustering of the isolated Nile tilapia $\alpha$-actins with other vertebrate and ascidian muscle actins in the same clade was strongly supported in $100 \%$ of bootstrap replicates. This strongly supported relationship between vertebrate and ascidian muscle actins has been already demonstrated by the comparison of diagnostic aa and phylogenetic analyses, suggesting that the chordate muscle-type actins probably diverged from a nonmuscle-like actin before the divergence of urochordates and vertebrates, but presumably after the divergence of echinoderms and chordates (Kusakabe et al., 1997). The actin genes allowed the discrimination of higher taxa, but

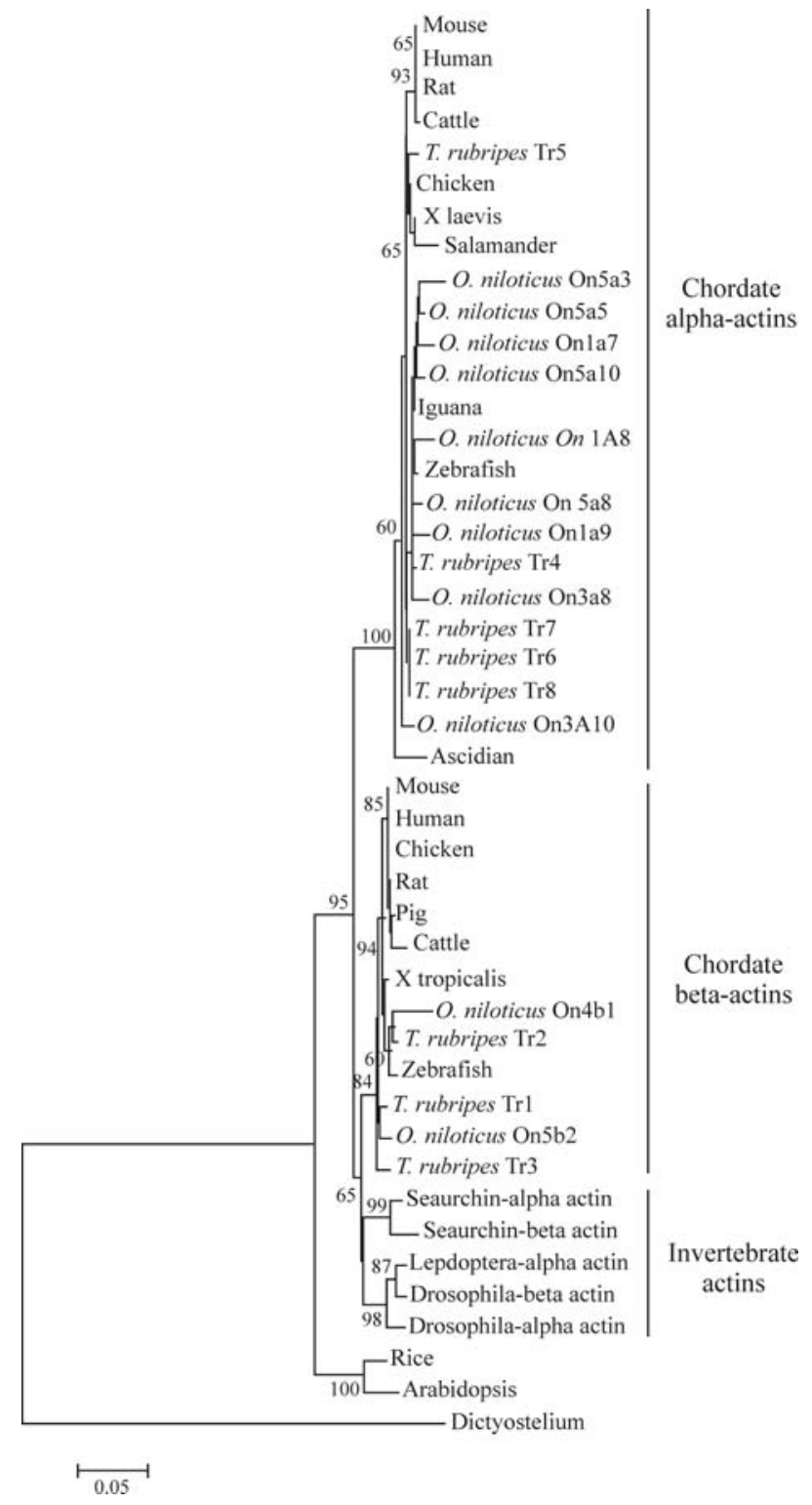

Figure 2 - Molecular phylogenetic tree inferred by the neighbor-joining method from predicted amino acid (aa) sequences of actin genes. The myxamoeba species Dictyostelium discoideum was used as an outgroup. Branch lengths are proportional to evolutionary distances. Scale bar indicates an evolutionary distance of 0.05 aa substituition per position in the sequences. The numbers at each node indicate the percentage recovery $(>$ $60 \%$ ) of the particular node (500 bootstrap replicates) in which the same internal branch was recovered. Sources and accession numbers for the actin sequences are described in Material and Methods.

were not informative for lower taxonomic levels because of the high conservation at DNA sequence level.

The clade composed of the isolated Nile tilapia cytoplasmic actins and vertebrate cytoplasmic actins is supported in $84 \%$ of the bootstrap replicates. An interesting point was the presence of invertebrate muscle and cytoplasmic actins in the clade of vertebrate cytoplasmic actins (tree node percentage recovery of $65 \%$ ). This relationship is in accordance with previous analyses that suggest that non- 
chordate muscle actin genes are more closely related to vertebrate cytoplasmic actins than to vertebrate muscle actins (Kusakabe et al., 1997). The actins expressed in muscle cells of non-chordates have traditionally been considered to be cytoplasmic-like (Vandekerckhove and Weber, 1984), and non-muscle actins are likely to represent ancestral actin forms.

As evidenced for other organisms, different fish actin types also seem to be under different evolutionary selection pressures, leading to the conjecture that these isoforms seem to have somewhat different roles. Further analyses comparing the organization of distinct actin isoforms from several species will be useful for understanding the molecular evolution and function of these genes in fishes.

\section{Acknowledgments}

This work was supported by grants from FAPESP (Fundação de Amparo à Pesquisa do Estado de São Paulo), CNPq (Conselho Nacional de Desenvolvimento Científico e Tecnológico), and CAPES (Coordenação de Aperfeiçoamento de Pessoal de Nível Superior).

\section{References}

Altschul SF, Gish W, Miller W, Myers EW and Lipman DJ (1990) Basic local alignment search tool. J Mol Biol 215:403-410.

Drouin G and de Sá MM (1996). Phylogeny and substitution rates of angiosperm actin genes. Mol Biol Evol 13:1198-1212.

Fang H and Brandhorst BP (1994) Evolution of actin gene families of sea urchins. J Mol Evol 39:347-356.

Fyrberg EA, Kindle KL and Davidson N (1980) The actin genes of Drosophila: A dispersed multigene family. Cell 19:365378.

Herman IM (1993) Actins isoforms. Curr Opin Cell Biol 5:48-55.

Hightower RC and Meagher RB (1986) The molecular evolution of actin. Genetics 114:315-332.

Kumar S, Tamura K and Nei M (2004) MEGA 3: Integrated software for molecular evolutionary genetics analysis and sequence alignment. Brief Bioinform 5:150-163.

Kusakabe T, Araki I, Satoh N and Jeffrey WR (1997) Evolution of chordate actin genes: Evidence from genomic organization and amino acid sequences. J Mol Evol 44:289-298.

Mounier N and Sparrow JC (1997) Structural comparisons of muscle and nonmuscle actins give insights into the evolution of their functional differences. J Mol Evol 44:89-97.

Mounier N, Guoy M, Mouchiroud D and Prudhomme C (1992) Insect muscle actins differ distinctly from invertebrate and vertebrate cytoplasmic actins. J Mol Evol 34:406-415.
Pullin RSV (1991) Cichlids in aquaculture. In: Keenleyside MHA (ed) Cichlid Fishes: Behaviour, Ecology and Evolution. Chapman \& Hall, New York, pp 280-309.

Reece KS, McElroy D and Wu R (1992) Function and evolution of actins. Evol Biol 26:1-34.

Reece KS, Siddall ME, Burreson EM and Graves JE (1997) Phylogenetic analysis of Perkinsus based on actin gene sequences. J Parasitol 83:417-423.

Rozen S and Skaletsky HJ (2000) Primer3 on the WWW for general users and for biologist programmers. In: Krawetz S, Misener S (eds) Bioinformatics Methods and Protocols: Methods in Molecular Biology. Humana Press, Totowa, pp 365-386.

Saitou N and Nei M (1987) The neighbor-joining method: A new method for reconstructing phylogenetic trees. Mol Biol Evol 4:406-425.

Thompson JD, Higgins DG and Gibson TJ (1994) Clustal W: Improving the sensitivity of progressive multiple sequence alignment through sequence weighting, position-specific gap penalties and weight matrix choice. Nucleic Acids Res 22:4673-4680.

Vandekerchkove J and Weber K (1978) At least six different actins are expressed in a higher mammal: An analysis based on the amino acid sequences of the amino-terminal tryptic peptide. J Mol Biol 126:783-802.

Vandekerckhove J and Weber K (1984) Chordate muscle actin differ distinctly from invertebrate muscle actins. The evolution of the different vertebrate muscle actins. J Mol Biol 179:391-413.

Venkatesh B, Tay BH, Elgar G and Brenner S (1996) Isolation, characterization and evolution of nine pufferfish (Fugu rubripes) actin genes. J Mol Biol 259:655-665.

\section{Internet Resources}

BLAST: The Basic Local Alignment Search Tool (BLAST) is a WWW service of National Center for Biotechnology Information (NCBI). Available from http://ncbi.nml.nih.gov/ blast/ (May 20, 2006).

ClustalW: WWW Service at the European Bioinformatics Institute. Available from http://www.ebi.ac.uk/clustalw (May 20, 2006).

GenBank: GenBank ${ }^{\circledR}$ is the National Institutes of Health (NIH) genetic sequence database, an annotated collection of all publicly available DNA sequences. Available from http://www.ncbi.nlm.nih.gov/GenBank/ (January 03, 2007).

Primer3: Primer3 is a widely used program for designing PCR primers. Available from http://fokker.wi.mit.edu/primer3/ (May 20, 2006).

Associate Editor: Pedro Manoel Galetti Junior

License information: This is an open-access article distributed under the terms of the Creative Commons Attribution License, which permits unrestricted use, distribution, and reproduction in any medium, provided the original work is properly cited. 